\title{
A UNIÃO SUBSTANCIAL CORPO-ALMA NO ÂMBITO DA NOVA CIÊNCIA CARTESIANA
}

Ligia Fraga SILVEIRA*

\begin{abstract}
RESUMO: As dificuldades enfrentadas por Descartes para pensar a união substancial corpo/alma, já que partiu da distinção real das duas substâncias. Uma tentativa de pensar essa união conflitante em termos de uma oposição por complementaridade.

UNITERMOS: Res extensa; res cogitans; união substancial; simetria; oposição; complementaridade; contradição.
\end{abstract}

É comum na abordagem da Ciência cartesiana reservar um espaço secundário à sua Medicina, pois esta não seria outra coisa que uma extensão dos resultados de sua Mecânica aplicada à fisiologia. Mas se bem observarmos, a Medicina levanta problemas especificos que nos levam a dimensionar mais amplamente a própria reforma do pensamento proposto por Descartes. Se se trata de uma Medicina do corpo humano, não podemos esquecer que para Descartes o homem é um composto de duas substâncias distintas ("res extensa" e "res cogitans") e uma interação entre elas não permite que se ignore como o autor terá que enfrentar esse dado em seu tratamento do corpo humano.

É sob este enfoque que desejamos examinar a complementaridade de duas substâncias opostas neste novo espaço epistemológico em que Descartes elabora sua nova ciência. Talvez possamos chegar a afirmar que Descartes distinguiu e opôs essas duas substâncias para pensar sob nova forma a união substancial. Assim, sua Medicina passa a ser não um simples ramo de sua ciência, mas o lugar onde realmente Descartes não só enfrenta suas maiores dificuldades, como também se trata do ponto crucial para superar as formas substanciais aristotélicas.

Para tanto, vamos explorar como a oposição por complementaridade entre "res extensa" e "res cogitans" tem um papel importante na nova Medicina cartesiana e mesmo numa psicofisiologia, revelando sua função num pensamento que se constrói em oposição ao pensamento aristotélico.

Preliminarmente devemos lembrar que, se não encontramos uma ciência categorial elaborada em Descartes, encontramos por outro lado oposições conceituais, que revelam um pensamento construtivo em marcha. Como todo o século XVII, que desatualizando a ciência aristotélica, deixa de lado como inúteis suas categorias, para a busca de uma nova metologia do conhecimento, Descartes, diferentemente do que mais

\footnotetext{
* Departamento de Filosofia - Faculdade de Educaçào, Filosolia.. Ciências Sociais e da Documentação - UNESP 17.500 - Marilia - SP.
} 
SILVEIRA, L.F. - A união substancial corpo-alma no âmbito da nova ciência cartesiana.

Trans/Form/Ação, São Paulo, 7:25-36, 1984.

tarde fará Kant, constrói sua nova ciência sem tomar conhecimento e sem pensar num remanejamento dessas categorias. Mas nem por isso seu pensamento deixa de ser categorial e é com ele que assistimos a distinção básica entre "res cogitans" e "res extensa”, que tornou possivel tanto uma ciência do mundo material, como uma análise do pensamento. Ainda mais, sob a forma de uma oposição por complementaridade destas duas substâncias, Descartes também elabora mesmo que embrionariamente uma ciência do homem, o que nos leva realmente a pensar que distinguir e opor, para em seguida pensar a complementaridade das duas substâncias é o cerne e a base de um pensamento que constrói seu próprio espaço, onde a nova ciência possa enfim se validar.

Partindo das Meditações, estas são fora de dúvida o momento crucial para Descartes encontrar uma fundamentação metafísica para uma ciência que anteriormente ele já concretizara. A partir da 2. ${ }^{\text {a }}$ Meditação onde nosso autor demonstra a distinção real entre "res extensa" e "res cogitans", está aberto o caminho para uma legitimação das ciências do mundo material e para as ciências do espírito. Sem nos determos nas etapas que rigorosamente, segundo a ordem das razões, nos levam até a 6. ${ }^{\text {a Meditação }}$ e a possibilidade dessas ciências, cremos que Gueroult sintetiza muito claramente esta finalidade. Como afirma “Après que la $5^{\mathrm{C}}$ Meditation, s'appuyant sur les conclusions de la $3^{\mathrm{e}}$ a fondé les mathématiques, la $6^{\mathrm{e}}$ par la preuve de la distinction de l'âme et du corps et celle de l'existence des corps, fonde la physique et une part de la médicine; par la preuve de l'union substantielle, elle fonde la psychologie (théorie des passions), une autre part de la médicine, une part de la morale"' $(9$, v.2, p. 12).

Mas devemos observar que, se o espaço epistemológico para cada uma dessas ciências está delimitado, nem por isso podemos afirmar tranquilamente que não haja dificuldades para a consecução das ciências que dizem respeito em particular ao homem. Se uma ciência do mundo material que se baseia somente na distinção das duas substâncias, pode mais facilmente ser legitimada e concretizada, as ciências tanto do corpo, como do espírito que dizem respeito ao homem, encontram dificuldades para. entrar dentro dos parâmetros da ciência cartesiana. O Tratado das Paixões da Alma é um exemplo dessas dificuldades.

Parece-nos, com efeito, que elas podem ser detectadas nas Meditações. Por mais paradoxal que seja, se essas Meditações tendem inteiramente para a conclusão da distinção real da alma e do corpo, não deixam num segundo plano a união substancial das mesmas. Nossa questão seria pois, porque essa necessidade de distinguir para depois unir, já que esta união vai ser problemática na lógica do pensamento cartesiano?

Segundo Gilson, isto revelaria o próprio paradoxo cartesiano: tendo em vista superar as formas substanciais aristotélicas, distingue "res extensa" e "res cogitans", mas admitindo u m caso de união substancial, tomaria alma como uma forma do corpo humano.

Vejamos um pouco a posição de Gilson que vai nos permitir compreender a oposição por complementaridade num pensamento que abre um espaço para a nova ciência $(8$, p.143-173; 245-255).

Descartes, segundo Gilson, teria que se posicionar e resolver o conflito entre a filosofia natural escolástica e a sua ciência. O ponto central deste conflito, e que sustentaria toda a física escolástica seria a noção de forma substancial. No entanto, Descartes não empreende inicialmente uma crítica para derrubar o sistema filosófico da escolástica a partir de seus fundamentos. A questão que se colocava mais imediatamente desde o encontro com Beeckman era como resolver e superar "la juxtaposition d'une physique pleine de hauts problèmes, mais sans méthode pour le resourdre, et d'une mathématique, dont la méthode était sûre, mais qui ne trouvait que de menus problèmes ou 
SILVEIRA, L.F. - A união substancial corpo-alma no âmbito da nova ciência cartesiana. Trans/Form/Ação, São Paulo, 7:25-36, 1984.

l'appliquer' (2, p.147). Isto o levou a praticar uma ciência independente da física escolástica sem se preocupar com uma crítica da mesma e muito menos em opôr uma filosofia a outra filosofia. Encontramos no Dicurso do Método uma confirmação deste encaminhamento citado, aliás, por Gilson. Diz Descartes: “Toutefois, ces neufans s'écoulérent avant que j'eusse encore pris auncun parti touchant les difficultés qui ont coutume d'être disputées entre les doctes, ni commencé à chercher les fondements d'aucune philosophie plus certaine que la vulgaire', (1, p.30, 1.10-14).

Mas no momento em que Descartes se propõe alargar seu projeto e explicar todos os fenômenos da natureza, isto é, toda a física, começa concomitantemente uma crítica das formas substanciais. Esta crítica em seu Traité de la Lumière aparece, segundo Gilson, solidária de uma outra tese: “que ce qui reléve de l'étendue ne doit pas être concue par analogie avec la pensée”, $(8$, p. 153$)$.

Para compreender a necessidade que se apresenta para Descartes neste momento de não conceber a matéria por analogia com o espírito, é necessário ver como o pensamento aristotélico concebia a natureza e o movimento.

A física é antes de tudo para Aristóteles uma explicação da mudança, tanto que entre todos os movimentos o mais fundamental é o aparecimento e a formação de um ser, isto é, o nascimento de um ser. Isto significa que a física aristotélica está revestida por um aspecto biológico, pois o movimento (entendido como mudança) está embasado sobre um fato biológico: o nascimento de um ser. Assim tanto os seres vivos como os seres inanimados participam dessa "fusis", enquanto tem neles mesmos o princípio de sua mudança e vão se opor simplesmente aos seres artificiais. Se há, pois, essa analogia com o princípio das operações próprias aos seres vivos e se este princípio é a alma, podemos concluir que é a alma que fornece ao físico o protótipo da natureza. A alma sería portanto um princípio constitutivo dos seres vivos e, por analogia, também dos seres inanimados. O que nos permite afirmar que, como princípio constitutivo, a alma é a própria natureza.

Sendo desta maneira a explicação das operações dos seres ditos naturais, esses seres têm neles mesmos a possibilidade de se mover isto é, uma faculdade e uma substância que lhes pertence. E se nas substâncias físicas, a matéria é o passivo, a forma seria o princípio gerador ativo, na formação desses seres naturais.

Com esses dados, podemos pressentir as implicações que podem ter no estudo do mundo da natureza e em particular do movimento, qualificado por Aristóteles de movimento natural. Ex: um corpo que cai, cai sozinho enquanto é pesado e podemos dizer que seu movimento é natural. Em outros termos, todo corpo pesado tem em si mesmo a potência de se mover. A causa do movimento dos seres inanimados é pois sua natureza ou forma e, ao mesmo tempo, para distingüi-los dos seres vivos, uma causa exterior que provoca esta mudança. Uma certa ambigüidade ai se encontra, devido ao próprio ponto de partida aristotélico, que trabalha o mundo dos seres inanimados por analogia com os seres vivos.

É lógico que na nova ciência praticada por Descartes isto é impossível. Toda e qualquer analogia do mundo da natureza inanimada com os seres vivos é deixada de lado. Seres naturais, movimentos naturais perdem o seu sentido, pois o campo de ação da física deixa de estar limitado por esta concepção de natureza, de "fusis". Como afirma Gilson: "Pour le physicien moderne, on peut dire que le nom de la science dont il s'occupe est à peu près complementement dépourvu de sens. Le mot "physique", n'est rien de plus à ses yeux que l'étiquette par laquell il désigne l'ensemble des lois, à base expérimentale et de formulemathemátique, qui sont pour lui la nature;...' (2, p. 153).

Em Descartes em seu Traité de la Lumière onde se lhe apresenta a necessidade de englobar todos os fenômenos da natureza, esta crítica dirige-se às bases sobre as quais a 
SILVEIRA, L.F. - A união substancial corpo-alma no âmbito da nova ciência cartesiana. Trans/Form/Ação, São Paulo, 7:25-36, 1984.

física aristotélica se constrói. Estabelece-se uma diferença entre a idéia que se forma em nossa imaginação e os objetos que produzem em nós um determinado sentimento. Decorrente desta diferenciação segue-se, num texto, aliás, igualmente citado por Gilson, a eliminação das formas substanciais. "Qu'un autre donc imagine, s'il veut en ce bois, la Forme du feu, la Qualité de la chaleur et l'Action qui le brûle, comme des choses toutes diverses; pour moi, qui crains de me tromper si j'y suppose quelque chose de plus que ce que je vois nécessairement y devoir être, je me contente d'y concevoir le mouvement de ses parties"' $(4$, p. $3,1.1 .-8)$. Há pois uma solidariedade entre a tese que tudo que é da ordem da extensão não deve ser confundido com o pensamento e uma crítica às formas substanciais. Estamos pois face à uma nova ciência que desaloja necessariamente a concepção tradicional de "fusis".

Assim podemos ver que o encaminhamento cartesiano exigido por sua prática científica o obriga a estabelecer uma distinção entre "res extensa" e "res cogitans". Voltando à 6. ${ }^{\text {a }}$ Meditação, assistimos da parte de Descartes a fundamentação metafísica desta nova ordem, oferecendo a possibilidade de validar a física do mundo da natureza e uma parte da Medicina, que decorrem do dominio da "res extensa".

Esta distinção se inseria na exigência interna destas novas ciências, considerada a parte da Medicina que trata do corpo animal. Descartes, contudo, deverá enfrentar tal distinção no mesmo nivel de exigência crítica no caso especial da natureza humana. Nela haverá a exigência de pensar uma complementaridade entre as duas substâncias. É neste ponto que queremos apresentar algumas questões que têm um interesse mais especifico. Trata-se de perguntar se realmente essas novas categorias cartesianas no interior de seu universo de pensamento, dão passo tão determinante como no caso da física do mundo da natureza, ou se algumas dificuldades vão dai decorrer no que diz respeito ao homem c às ciências que lhe dizem respeito.

Podemos observar nas obras que tratam do homem, tais como Traité de l'Homme (5), a 5. " parte do Discours de la Méthode (1), La Description du corps humain (2) e o Traité des passions de l'âme(6), Descartes inicia salientando que para pensarmos a união substancial precisamos preliminarmente distingüir as funções e movimentos corporais das funções da alma. A finalidade é evitar atribuir a esta o que é exclusivamente da ordem do corporal.

Isso nos parece sintomático por duas razões:

1. ') A união das duas substâncias opostas é o que deve ser afirmado como a natureza humana;

2. $\left.{ }^{a}\right)$ e que a distinção, oposição e complementaridade ao mesmo tempo que inovam uma abordagem do corpo humano em suas funções, distingüindo-as das funções da alma, propõem-se pensar uma interação, que desvenda uma região psico-física.

Em todos esses Tratados, tal problemática está sempre presente.

Baseando-nos nestas duas razões, perguntamos se essas oposições conceituais e sua possivel complementaridade superam realmente as formas substanciais aristotélicas. Ou, se no caso do homem, a alma não seria a forma do corpo.

Quando Descartes pretende estender os frutos de sua ciência do mundo da natureza ao estudo do corpo humano, a ef etivação deste projeto traz realmente um avanço em relação ao aristotelismo. A eliminação do animismo atinge também a explicação dos movimentos e funções corporais. Dentro dos parâmetros da ciência cartesiana, sua fisiologia goza dos mesmos avanços de sua física. Os textos citados acima exemplificam fartamente esse objetivo. A suposição de pensar o corpo humano em comparação com a engrenagem de uma máquina, que tal qual a máquina criada pelo homem passa a se sustentar por si mesma, parece aos olhos de Descartes uma hipótese explicativa sustentável. Esta hipótese torna inútil o apelo a uma alma vegetativa, sensitiva e mes- 
mo racional para a explicação desses ef eitos que são os movimentos e as funções corporais, dependentes de agora em diante unicamente da disposição dos órgãos. Exclui-se, portanto, qualquer contaminação na explicação e descrição do corpo humano, tanto quanto já se observou no seu tratamento do mundo da natureza, das bases antropomórficas do pensamento aristotélico. No entanto, este tratamento explicativo do mundo da natureza incluindo a explicação do corpo humano, como todo mecanismo continua exigir um finalismo. Um Deus “ex machina”, criador e "modelador” do mundo, isto é, causa final do mundo, ainda povoa o universo filosófico de Descartes.

Mas se a partir de Descartes houve por um lado, a liberação de um mecanismo para a explicação do mundo material e, por outro lado, de um puro espiritualismo, vemos que para o próprio autor tais resultados não parecem satisfatórios. Como já vimos o ponto culminante da crítica cartesiana das formas substanciais era a análise feita do erro aristotélico. Para ele a origem das noçòes de forma e qualidade era explicada por uma espécie de contaminação da natureza física pela experiência humana da união da alma com o corpo. Isso significa que essa experiência é um fato e é a partir deste fato, como muito bem afirma Gilson no texto já citado, que o homem inventou as formas substanciais.

É sob este aspecto que afirmamos que em Descartes é tão importante a união como a distinção entre "res extensa" e "res cogitans". Em todas as obras citadas sobre o homem, é em vista de se chegar a explicar a união substancial que os frutos da distinção se encaminham como etapa preliminar e necessária. E a 6. "Meditação dá demonstração da distinção das duas substâncias e da existência dos corpos (1. ' e 2. " prova), como da união substancial $\left(3 \text {. }^{\mathrm{a}} \text { prova }\right)^{*}$.

No entanto, vale ressaltar que se a distinção é da ordem do entendimento, esta união é da ordem do vivido. O novo instrumento de conhecimento é o sentimento e esta união substancial escapa, pois, de ser abarcada pelo entendimento. Nossa questão é se esta união substancial atestada pelos sentimentos até que ponto não faz reaparecer o problema do erro em Aristóteles e, concomitantemente, a questão das formas substanciais. Logicamente, quais são as conseqüências para sua Medicina e sua ciência integral do homem.

Vejamos primeiramente qual a função dos sentimentos na demonstração desta união como substancial e não acidental, tal qual encontramos nas Meditações (3). Como afirma Descartes, “La nature m'enseigne aussi par ces sentiments de douleur, de faim, de soif, etc, que je ne suis pas seulement logé dans mon corps, ainsi qu'un pilote en son navire, mais outre cela, que je lui suis conjoint très étroitement et tellement confondu et mêlé, que je compose comme un seul tout avec lui' ' (3, p. 64).

Os sentimentos são, portanto, para Descartes, maneiras confusas de pensar que provêm e dependem da união do espírito com o corpo e que esta união não é meramente acidental, como se a alma estivesse alojada em meu corpo, mas uma união muito estreita que só pode ser considerada como substancial. É algo que vamos ver sendo afirmado, constituindo a própria razão de ser do Tratado das Paixões, onde essa interação corpo e alma é examinada em detalhes.

Mas esses sentimentos que atestam a união substancial, são sentimentos que concernem a ordem do vivido e, portanto, são abordados não em seu conteúdo representativo, nem mesmo em sua variedade qualitativa, mas no aspecto obscuro e confuso da qualidade. Assim, se na $4 .{ }^{a}$ Meditação que trata do verdadeiro e do falso do ponto de

\footnotetext{
* Nota: para a análise das Med. baseamo-nos em Gueroult, Descartes selon l'ordre des raisons
} 
SILVEIRA, L.F. - A união substancial corpo-alma no âmbito da nova ciência cartesiana.

Trans/Form/Ação, São Paulo, 7:25-36, 1984.

vista formal, o erro, fruto de nossa liberdade, é reconhecido um mal para o homem, nesta $6 .^{a}$ Meditação, o materialmente falso para o entendimento deverá receber uma função útil para o homem. É o que Descartes afirma quanto às percepções dos sentidos que "les unes me sont agréables, et les aụtres desagréables je puis tirer une consequence tout à fait certaine, que mon corps (ou plutot moi-même tout entier, en tant que je suis composé du corps et de l'âme) peut recevoir diverses commodités ou incomodités des autres corps qui l'environnent', (3,p.64-65).

Mais adiante, explicando como o espírito não recebe imediatamente a impressão de todas as partes do corpo, mas do cérebro, afirma "puisque de tous les mouvements qui se font dans la partie du cerveau dont l'esprit reçoit immediatement l'impression, chacun ne cause qu'un certain sentiment, on ne peut rien en cela ressentir à l'esprit, entre tous les sentiments qu'il est capable de causer celui qui est le plus propre et le plus ordinairement utile à la conservation du corps humain', $(3, \mathrm{p}$.69-70).

Disto decorre que os sentimentos que são o resultado desta interação e conjunção corpo e alma tem um valor de informação biológica relativo a minha natureza psicofísica e, portanto, apresenta como função assegurar a conservação desta natureza. Em outros termos, os ensinamentos dos sentidos têm como função específica significar para meu espírito quais as coisas que são convenientes ou nocivas ao composto do qual ele faz parte. Esta é a descoberta pelo entendimento da verdade intrínsica dos sentidos, isto é, sua função de conservação biológica. Desta maneira, o sentimento é reintegrado na esfera do saber.

Mas esta reintegração supõe que mesmo as falhas de nossa natureza não invalidam esta finalidade interna que a regula e que revela como diz Gueroult "l'intention bienveillante qui a présidé à leur composition la verité des enseignements biologiques du sens, nés de l'union substantielle, s'appuie, non sur la realité objective de la sorte de pensée (sentiment) qui résulte de cette union, mais sur l'appropriation optima aux besoins du composé de la structure impartie à ce dernier par la bonté du créateur... C'est également le principe du meilleur qui, dans ma nature composée, amène Dieu à unir substantiellement une partie du divisible à l'indivisible par une structure psychophysique telle que le sens remplisse sa fonction de la meilleur façon possible pour nous et soit para là justifié, malgrè la faillibilité à laquelle il est exceptionnellement exposé' ( 9 , p. 269).

Assim, o Deus veraz que na $3 .{ }^{\text {a }}$ Meditação garante o valor objetivo das idéias fruto do meu entendimento, aqui na 6. ' Meditação reaparece sendo desculpado dos nossos erros no plano vivido. Se é pelo princípio do melhor que a bondade do criador em sua intenção benevolente o leva a unir substancialmente duas substâncias distintas que formam minha estrutura psicofísica, está garantindo que o sentido possa preencher sua função da melhor maneira possível, em vista da preservação do composto.

É ao que chegamos na Metafísica cartesiana como demonstração substancial do corpo e da alma e que vai se apresentar de suma importância no tratamento especial que o corpo humano goza na filosofia de Descartes.

Mas se o erro é desculpado desta maneira, as conseqüências destas conclusões da 6. ${ }^{\text {a }}$ Meditação para as ciências do homem podem ser observadas nos Tratados que citamos acima em que, após distinguir as funções da alma das funções do corpo, principalmente no "Tratado das Paixões da Alma"' empreende a questão da união. É nesta obra que podemos ver aparecer elementos importantes para essa nova região que embrionariamente aparece na filosofia cartesiana, isto é, a região psicofísica. Mas não podemos afirmar que seja tranqüilo este espaço epistemológico que se abre para uma ciência desta região. Essas dificuldades podem ser levantadas a partir das dificuldades de pensar uma união de duas substâncias distintas e completas em si mesmas. 
Fernando Gil, em seu artigo "O Pensamento Categorial das simetrias às contradições”' (1) nos dá elementos valiosos e básicos para enfrentarmos as dificuldades que encontramos em Descartes.

Inicialmente dissertando sobre as formas de oposição conceitual, define a oposição por complementaridade em termos de pares não antagonistas. Se não são antagonistas, a mediação entre eles é fornecida pelo próprio "todo' de que os termos complementares são as determinações. No entanto, o fundamento desta unidade é difícil de ser apreendido. Mas ainda, ao contrário das simetrias que também são oposições não antagonistas as complementaridades implicam numa cooperação conflitual.

Nada melhor para caracterizar as relações que Descartes estabelece entre "res extensa" e "res cogitans", Distinguir e opor para depois pensar a união e a cooperação, é o intuito de nosso autor.

Se Descartes partiu da oposição pelos motivos que já assinalamos acima, um fato no entanto não pode ser negado: a experiência humana da união. E é este fato que novamente volta a ser requerido na ordem do vivido e reintegrado na ordem do saber como prova da união substancial. Mas essa experiência da união, como já vimos, é obscura para o entendimento e neste sentido só podemos experimentá-la pelo uso da vida. Em outros termos, o que foi criticado no plano do entendimento na explicação dos seres inanimados por analogia com os seres vivos, passa a ter um papel especial na própria antropologia cartesiana.

Mas se é um fato e por isso mesmo indiscutivel, isso não significa que não existe problemas, dificuldades. Abundam as explicações em que o autor tenta coadunar sua explicação mecânica do corpo e o fato deste corpo estar unido ao espírito. Mesmo uma glândula pineal é inventada para explicar a inserção da alma no corpo. Toda sua preocupação é mostrar que a união não é acidental e que mesmo conflitante a interação entre essas duas substâncias opostas se explica pela própria experiência da união, deste todo que nós somos.

Gilson enfrenta esta dificuldade em Descartes afirmando que este "utilize une méthode nouvelle pour retrouver d'anciennes réalités"' (8, p. 253). Por ex.: Deus, a alma, a união substancial, etc. Mas não se pode negar este novo método mesmo que seja para reconstruir antigas realidades. O pensamento de Descartes com todas as suas dificuldades revela esse caráter flutuante de todo o século XVII que tenta construir um espaço epistemológico para a ciência moderna nascente.

Em Descartes este problema aparece pela reconstituição, como afirma Gilson, “par compositions d'idèes distintes e antithétiques, des notions voulues par la scholastique en raison de leur complexité même. Le tout n'étant le tout que parce qu'il n'était pas fait de deux morceaux isolables, Descartes, qui se donne d'abord deux morceaux, ne reussit plus à les rejoindre pour en faire un homme', $(8$, p. 254). Se essas duas noções opostas estão aí para pensar duas substâncias completas em si mesmas, é lógico que a alma como forma do corpo, formando uma única substância como pensava a escolástica, não pode partir da suposição de duas substâncias completas em si mesmas.

A união, porém, é para Descartes um fato, e como tal experimentado. Concernindo a ordem do vivido, uma explicação pela complementaridade de duas noções opostas é no nível categorial um recurso epistemológico que está na base de sua tentativa de validar uma ciência do homem enquanto corpo e alma.

Vejamos como isso se faz e, como trabalhando com antigas noções, Descartes abre um espaço, mesmo que precário, a uma psicofísica. Nossa tese é que, tendo distinguido para unir, não só cria dificuldades para o seu ideal de ciência que se formou através de sua Física como também abre uma brecha para a problemática região humana. É sintomático que Descartes passe das abordagens do mundo dos seres inanimados, di- 
retamente para tratados que dizem respeito ao homem. Os outros seres vivos não são uma preocupação, embora os seres inanimados e o homem o sejam.

Assim, mesmo que dominado como propõe Gilson, por antigas noções a serem incorporadas a sua nova ciência, Descartes com suas novas categorias realmente abre um horizonte para uma psicofísica. É de grande interesse seu Tratado das Paixões da Al$m a$, pois aí o velho e o novo se encontram e certos limites aparecem no seu ideal de ciência. Analisando alguns pontos importantes desta obra, podemos observar uma problemática das limitações e dos esforços para enfrentar a complexidade do ser humano.

$\mathrm{Na} \mathrm{1.} \mathrm{a} \mathrm{parte} \mathrm{que} \mathrm{trata} \mathrm{“Des} \mathrm{passions} \mathrm{en} \mathrm{general} \mathrm{et} \mathrm{par} \mathrm{occasion} \mathrm{de} \mathrm{toute} \mathrm{la} \mathrm{nature}$ de l'homme', temos uma ocasião especial de ver Descartes se apoiar nos resultados de sua fisiologia e mesmo resumi-la naquilo que o interessa no momento. É no que se sente seguro para delimitar o que podemos chamar de paixões da alma no sentido restrito. “Or encore que toutes nos perceptions, tant celles qu'on rapporte aux objets qui son hors de nous que celles qu'on rapporte aux diverses affections de notre corps, soient veritablement des passions au regard de notre âme, lors qu'on prend ce mot en sa plus generale signification: tourtefois on a coustume de le restreinde à signifier seulement celles qui se rapportent à l'âme même. Et ce ne sont que, ces dernières, que j'ai entrepis ici d'expliquer sous le nom de passions de l'âme' (6, p. 347, 1.25; p. 348, 1.4).

Assim se no Traité de l'homme Descartes está preocupado em descrever os movimentos e as afecções corporais, que afetam, não há dúvida alguma, a alma, aqui, no Traité des Passions de l'Âme, visa tratar somente das paixões que se ligam diretamente à alma. Assim no art. XXVII, em sua definição das paixões da alma, afirma que se trata “'Des perceptions, ou des sentiments ou des émotions de l'âme, qu'on rapporte particulièrement à elle, et qui sont causées, entretenues et fortifiées par quelque mouvement des esprits" (6, p. 349, 1.1-16). Nos dois artigos que seguem faz uma distinção entre ações e paixões da alma, isto é, as ações que decorrem de uma deliberação da vontade, e as paixões, que revelam em sua obscuridade não constituirem percepções evidentes, pois são fruto da interação do corpo e cla alma. São emoções da alma que modificam seu estado, agitando-a e perturbando-a e, por isso mesmo, algo "sof rido" pela alma.

Há pois uma diferença entre três espécies de "sentimentos”, a que se pode chegar pela distinção e interação das substâncias:

- os sentimentos que se ligam aos objetos exteriores, como os odores, os sons etc.;

- os sentimentos que se ligam ao nossc corpo como a fome, a sede, a dor. Essas duas espécies de sentimentos tendo sido objeto de estudo do Traité de l'Homme e da Description du Corps Humain).

— os sentimentos que se ligam particularmente à alma e que são causados, entretidos e fortificados por movimentos dos espíritos animais (corporais), distinguindo-os portanto de nossas vontades que são causadas pela própria alma.

Assim, define-se o objeto de estudo deste Tratado, que se propõe descrever e explicar nesta interação corpo-alma, o que é causado pelos espíritos animais e que se liga particularmente à alma, como sendo seus sentimentos ou suas emoções.

Mas antes de descrever as paixões da alma, Descartes coloca a questão de como se dá essa união de duas substâncias distintas. Se a união é um fato, como explicá-la em termos de dar conta deste fenômeno, que são as paixões.

Primeiramente, como afirma o art. XXX, a alma só pode estar unida conjuntamente a todas as partes do corpo, pois não só o corpo como um ser vivo é um todo, que se mantém em razão da disposição e relações de seus órgãos entre si, como também a 
SILVEIRA, L.F. - A união substancial corpo-alma no âmbito da nova ciência cartesiana.

Trans/Form/Ação, Sào Paulo, 7:25-36, 1984.

alma enquanto substância espiritual indivisivel e distinta da substância corporal, só pode se ligar ao conjunto dos órgãos que fazem nosso corpo.

No entanto, Descartes não se satisfaz ai e passa a requerer um ponto de inserção corporal da alma. E este ponto corporal é a famosa glândula pineal que se localiza no cérebro. Nos arts. XXI, XXXII e XXXIII desta $1 .{ }^{a}$ parte, Descartes mostra a necessidade de um ponto que seja único e não duplicado, onde a alma possa exercer suas funções. É no cérebro “à cause que c'est à lui que se rapportent les organes des sens", mas não difusamente em todo o cérebro e sim na "plus intereure de ses parties, qui est une certaine glande fort petite, située dans le milieu de sa substance, et tellement suspendue au dessus du conduit par lequel les esprits de ses cavités antérieures ont communication avec ceux de la posterieure, que les moindres mouvements qui sont en elle peuvent beaucoup pour changer le cours des esprits, et reciproquement que les moindres changements qui arrivent au cours des esprits, peuvent beaucoup pour changer les mouvements de cette glande". Portanto, "La raison qui me persuade que l'âme ne peut avoir en tout le corps aucun autre lieu que cette glande ou elle exerce imediatement ses fontions, est que je considere que les autres parties de notre cerveau sont touts doubles...' $(6$, p. $352,1.4 ;$ p. $353,1.1$ e 1.11-21).

Pode-se perceber se é difícil pela própria completude de ambas as substâncias explicar o todo, mais problemático é compreender a inserção da alma enquanto espírito num ponto corporal. Se a escolástica não tinha esta dificuldade é porque tranqüilamente, baseando-se no aristotelismo, propunha a alma como forma do corpo. Em Descartes, quando se trata de passar do fato da união a uma explicação do mesmo, já que a alma não pode ser vista como o piloto de um navio (que no caso é o corpo), quase uma natureza corporal. Gilson, no texto que citamos acima, mostra essas dificuldades.

Cremos que são dificuldades inevitáveis num momento de passagem para uma nova ordem de pensamento. Após Descartes, podemos entender melhor tanto um puro espiritualismo quanto um puro materialismo. Mas nele os conflitos não estão ainda resolvidos.

Mesmo não resolvidos, há, no entanto, algo que consideramos importante. Como já dissemos acima, a distinção das duas substâncias foi primordialmente frutuosa para desatualizar a explicação aristotélica dos seres inanimados e, como consequiência, evitar uma explicação animista das funções corporais. E se há uma complementaridade e mesmo uma dependência simétrica de ambas as substâncias para formar e conservar o composto, um espaço se abre para uma medicina psicossomática. O Traité des Passions de l'Âme e sua vasta correspondência com a princesa Elisabeth são um farto material da preocupação de Descartes com esta interação corpo-alma, e conseqüentemente com uma medicina do corpo e da alma. O binômio Medicina-Moral para o pleno conhecimento que o homem deve ter de si mesmo, é, pois, a região onde esta preocupação se concentra.

Não há dúvida que é nesta área que as dificuldades e os limites de seu ideal de ciência vão-se processar. Gueroult tem uma posição a respeito em sua obra "Descartes, selon l'ordre des Raisons', Após sua análise da 6. "Meditação, aborda as conseqüências relativas à Medicina e à Moral (9, v.2, p. 219-271), englobando outras obras de Descartes que tratam da questão. A pergunta, se a Medicina Humana e a Moral podem constituir-se como ciências, o autor desenvolve numa 1. " etapa preliminar que "Médecine et Morale se presentent au premier abord, l'une et l'autre... comme des tecniques applicant une science certaine à la realization de fins concernant notre vie présent ' ( 1 , v.2, p. 240). Segundo Gueroult, se estamos diante de áreas que dizem respeito ao homem ou à natureza humana, enquanto é este composto substancial alma e corpo, a matéria que nos é oferecida é intrinsecamente obscura e confusa, como mostra a 3. ${ }^{a}$ prova 
SILVEIRA, L.F. - A união substancial corpo-alma no âmbito da nova ciência cartesiana. Trans/Form/Ação, São Paulo, 7:25-36, 1984.

cartesiana. Assim, se em Descartes a Medicina, como já vimos, compreende uma ciência do corpo humano como pura máquina e se coloca enquanto tal como simples desenvolvimento da física, trata-se de uma ciência que compreende nela mesma ou em sua constituição somente idéias claras e distintas. Mas, ao mesmo tempo, há em Descartes uma ruptura entre o que ele chama corpo animal e corpo humano, e, sob este prisma, se o corpo animal pode ser considerado como pura máquina, o corpo humano em sua união substancial com uma alma se encontra face ao sentimento, que tem como função a preservação do composto. Da mesma maneira, a Moral terá que se defrontar com o problema das paixões, que são eminentemente expressões de nossa natureza psicofísica.

Desta maneira, na interpretação de Gueroult, a Medicina e a Moral Humana são sucedâneos da verdadeira ciência. Segundo o autor, "La vérité dont les disciplines tournées vers la vie requièrent la connaissance, c'est celle des moyens permettant de reáliser les fins suprêmes de cette vie; la santé du corps d'une part, le contentement de l'âme de l'autre, bref la vérité, ici, c'est l'utile. Au point de vue de l'entendement seul, l'utile réside entièrement dans les sciences exactes (mathématique, physique, médecine mécaniste), dans leurs applications pratiques: inventions de machines qui soulagent le travail humain, découvertes anatomiques et biologiques qui permettent d'améliorer les bonnes dispositions du corps et des les entretenir etc. Sur ce plan, la médecine apparait comme enveloppant une science aussi especulative que la physique', (9, p. 242-243). E, mais adiante, “C'est faut de savoir, sur ce plan satisfaire aux exigences de la vie, et par rapport à cet idéal mathemático-déductif, que se définira le succédané de science. A défaut de l'utilité dérivée des sciences exactes la volonté commande à l'entendement de découvrir des connaissances biologiquement et moralement utiles d'un ordre tout different des applications tecniques de la science exacte et situées sur un plan radicalement heterogène à celui de la vérité spéculative'... “dans cette sphere, la vérité ne concerne nullement la nature des choses, mais l'utilité biologique de ces choses par rapport à notre substance composée', (9, p. 243).

A colocação de Gueroult parece-nos extremamente importante para aquilo que nos interessa. Distinguimos dois niveis de utilidade em Descartes: um eminentemente prático, que visa à aplicação das ciências exatas para aliviar o trabalho humano (a invenção das máquinas) e melhorar a boa disposição do corpo, que são respectivamente a Mecânica e a Medicina; outro cuja utilidade como sucedânea da 1. ${ }^{a}$, vê a utilidade biólógica destas coisas que pelas ciências exatas conhecemos pelo entendimento sua natureza. Assim, para Gueroult, tanto a Medicina como a Moral são requeridas pela própria condição humana, enquanto somos um corpo unido substancialmente a uma alma. Mais ainda, como sucedâneos das ciências exatas, esta Medicina e esta Moral, como afirma Gueroult, ou, melhor dizendo, a verdade prática que as envolve "rentre entièrement dans la vérité théorique exacte', (9, p. 243).

No entanto, colocamos algumas ressalvas quanto a Medicina e Moral como sucedâneos da verdadeira ciência. Se Gueroult retrata muito bem a reintrodução da ordem do vivido no pensamento cartesiano, sem que isso signifique uma redução à ordem do entendimento, não concordamos que a Medicina e Moral sejam simples sucedâneos de sua verdadeira ciência.

Pelos motivos já levantados anteriormente, consideramos que muito mais que sucedâneos, essas duas áreas do saber começam a se apresentar conjuntamente. E é este propósito de Descartes que revela a delimitação mesmo que precária de uma ciência do composto humano. Se distinguir as duas substâncias impulsionou a sua ciência do mundo da natureza e desmistificou uma abordagem animista do corpo humano, o ter assumido, por outro lado, a experiência de união substancial revela também não redu- 
zir o mundo humano ao mundo da pura mecânica. Se Gueroult não ignora esses fatos da investigação cartesiana, não lhes dá, porém, importância devida.

Até que ponto não podemos afirmar que a autonomia que encontrou para a sua ciência do mundo da natureza, permitiu também a Descartes encabeçar uma autonomia para uma ciência do corpo e da alma? Esta autonomia, apesar de embrionária, possibilitou delimitar a região psicofísica no âmbito do pensamento de Descartes.

Se a oposição e a complementaridade entre "res extensa" e "res cogitans" deu ensejo a tais avanços, encontramos alguns limites a serem observados. Voltando à proposta de F. Gil para pensarmos oposição e complementaridade, poderemos compreender melhor as dificuldades de Descartes. Analisando as complementaridades e as dificuldades de inteligibilidade que lhes são inerentes, é quase natural que a questão sobre sua causa situa-se entre as simetrias e as contradições. As complementaridades herdam das primeiras "a idéia de uma estabilidade obtida a partir de uma com-posição; e anunciam o regime de incompatibilidade exaustiva e exclusiva dos contraditórios. Partindo da pluralidade contrastante da experiência, conservam uma raiz de certo modo empírica no sentido em que elas se verificam. E suscitam uma questão sobre a condição de possibilidade do pariamento, isto é, sobre sua causa.' (7, p. 190).

Esta colocação esclarece satisfatoriamente o fato de Descartes ter partido da união como um fato e como é difícil pensar as condições de possibilidade desta união. Tratando-se de uma com-posição de substâncias opostas e completas em si mesmas, constitui-se ao mesmo tempo, numa com-posição conflitante. Descartes no Traité des Passions..., em vários momentos tenta mostrar que apesar dos conflitos, um equilibrio é possível tendo em vista a preservação do composto. O sentimento, com sua função de informação biológica, é valorizado na explicação cartesiana, tanto quanto os elementos de ordem moral que fortaleçam esse equilibrio. Virtude e felicidade também fazem parte deste jogo para superar os conflitos.

E como já tínhamos visto antes, o erro no plano do vivido encontra justificação pois a intenção divina que presidiu esta composição tem como finalidade a preservação do composto. Deus é invocado como aquele que presidiu esta união e que, em sua bondade, apesar das falhas de nossa natureza, lhe dá quase que um “instinto” de preservação do composto.

Uma finalidade é invocada e que, escapando ao entendimento que distingue, se apresenta como uma finalidade que se manifesta nesta função dos sentimentos.

É o que F. Gil exprime quando afirma "porque as complementaridades são um fato, a sua justificação tende facilmente a assumir o aspecto de um "Deus ex machina", (7, p. 190), isto é, explicação da união substancial que escapa aos limites de uma explicação pelo entendimento, exigindo a interferência não somente de um Deus causa eficiente, mas também causa final daquilo que experimentamos pelo uso da vida.

Somente Kant, que eliminando Deus como causa final do mundo, pode liberar uma verdadeira antropologia. São esses apelos ainda antropomórficos na estrutura do pensamento cartesiano que nos levam a endossar as conclusões de Gilson quanto a Descartes ainda dominado pela escolástica e pelos paradoxos aos quais inevitavelmente se enreda. Não podemos, no entanto, ignorar que é com Descartes que um novo espaço epistemológico começa a ser justificado no plano filosófico. Crise e inovação fazem parte deste universo do pensamento que caracterizam Descartes e todo o Século XVII. É sob este enfoque que podemos compreender as estratégias conceituais de Descartes para validar sua ciência do mundo da natureza e sua Medicina do corpo e da alma. 
SILVEIRA, L.F. - A união substancial corpo-alma no âmbito da nova ciência cartesiana. Trans/Form/Ação, São Paulo, 7:25-36, 1984.

SILVEIRA, L.F. - The substantial union body/sou! in the new Cartesian science. Trans/Form/Acão. Sào Paulo, 7:25-36, 1984.

ABSTRACT: The difficulties faced by Descartes to think about the body/soul substancial union, since he started from the real distinction of both the substances. An attempt to consider this conflicting union by means of a complementarity oposition.

KEY-WORDS: Res extensa; res cogitans; substantial union; symmetry; opposition; complementarity; contradiction.

\section{REFERÊNCIAS BIBLIOGRÁFICAS}

1. DESCARTES, R. -- Discours de la Méthode. Oeuvres de Descartes. Publiées par Adam et P. Tannery. Paris, J. Vrin, 1965. t.VI.

2. DESCARTES, R. - La Description du Corps Humain. Oeuvres de Descartes. Publiées par Adam et P. Tannery. Paris, J. Vrin, 1974. t.XI.

3. DESCARTES, R. - Meditations. Oeuvres de Descartes. Publiées par Adam et P. Tannery. Paris, J. Vrin, 1973. t.IX-I.

4. DESCARTES, R. - Traité de la Lumiére. Oeuvres de Descartes. Publiées par Adam et $\mathrm{P}$. Tannery. Paris, J. Vrin, 1974. t.XI.

5. DESCARTES, R. - Traité de l'Homme. Oeu- vres de Descartes. Publiées par Adam et $\mathrm{P}$. Tannery. Paris, J. Vrin, 1974. t.XI.

6. DESCARTES, R. - Traité des Passions de I'Ame. Oeuvres de Descartes. Publiées par Adam et P. Tannery. Paris, J. Vrin, 1974. t.XI.

7. GIL, F. - O pensamento categorial: das simetrias às contradições. Versão portuguesa de Coppie Filosofiche. Torino, Enciclopedia Einaudi, 1978. v.3.

8. GILSON, E. - Etudes sur le rôle de la pensée médievale dans la formation du systeme cartesien. Paris, J. Vrin, 1967.

9. GUEROULT, M. - Descartes selon I'ordre des raisons.Paris, Aubier, 1953, v. 1-2. 